\title{
Síndrome de desconexión del conducto pancreático principal
}

\section{Disconnected Pancreatic Duct Syndrome}

\author{
Andrés Domínguez ${ }^{1}$ Maximiliano Noceti ${ }^{1}$ \\ ${ }^{1}$ Fundación Escuela de Medicina Nuclear (FUESMEN), Ciudad de \\ Mendoza, Mendoza, Argentina
}

Rev Argent Radiol 2018;82:83-85.

\begin{abstract}
Address for correspondence Andrés Domínguez, MD, Fundación Escuela de Medicina Nuclear (FUESMEN), Garibaldi 405, CP: 5500, Mendoza, Argentina (e-mail: andresdominguez82@gmail.com).
\end{abstract}

Estimados editores,

El síndrome de desconexión del conducto pancreático principal o síndrome del ducto pancreático desconectado (SDPD), es una complicación de la pancreatitis necrohemorrágica donde se genera una disrupción del ducto pancreático, con una porción viable de páncreas proximal al área de necrosis que continúa cumpliendo con su función exocrina, por lo cual los fluidos secretados comienzan a acumularse en una colección intra o peripancreática de tórpida evolución, pudiendo generarse también una fístula externa. ${ }^{1,2}$

Se presenta un caso de un varón de 24 años de edad cursando una pancreatitis aguda necrohemorrágica, donde en el estudio tomográfico inicial se detectó un área de necrosis a nivel del cuerpo pancreático menor a $1 \frac{1}{3}$ del parénquima con una pequeña colección post-necrótica aguda asociada. Se realizó una resonancia magnética (RM) de control unas 5 semanas luego de comenzado el cuadro, donde se observó una colección heterogénea a nivel del cuerpo del páncreas por presencia de debris, compatible con un área de necrosis encapsulada o walled off necrosis (WON). La porción caudal del páncreas presentaba adecuado realce post-contraste y en las secuencias de colangio-RM se identificó un páncreas de configuración divisum como probable causal del cuadro. Además, pudo demostrarse la relación del conducto pancreático principal con la colección, a la cual ingresaba en un ángulo de $90^{\circ}$ (-Fig. 1). Con esos hallazgos se planteó como posibilidad una desconexión del ducto pancreático principal.

El paciente fue manejado con tratamiento médico con varios reingresos y reagudizaciones del cuadro, realizando nuevo control imagenológico 7 semanas más tarde, donde se constató un aumento de tamaño de la colección. Finalmente se realizó drenaje de la colección mediante ecoendoscopía

received

April 12, 2017

accepted

November 29, 2017

published online

May 15, 2018
DOI https://doi.org/

10.1055/s-0038-1639493.

ISSN 1852-9992. por vía transgástrica, con colocación de prótesis a nivel del ducto, con buena evolución post-quirúrgica hasta la fecha.

La desconexión del ducto pancreático principal constituye una complicación subdiagnosticada de la pancreatitis necrohemorrágica, cuya prevalencia no es del todo conocida, aunque se calcula que aproximadamente un 10 a $30 \%$ de las pancreatitis graves la desarrollarán. ${ }^{2-4}$ Su mayor incidencia se da en pancreatitis graves con necrosis encapsulada (WON) tratadas con drenaje percutáneo, donde alcanza aproximadamente el $50 \%{ }^{5}$

Debe sospecharse de esa entidad en el contexto de una pancreatitis aguda necrohemorrágica, especialmente cuando las colecciones o la necrosis afectan predominantemente a la zona central del páncreas. ${ }^{2}$

La pancreatitis litiásica es la etiología más frecuente, sin embargo existen otras causas como el alcoholismo, traumatismo y el páncreas divisum, siendo ese último nuestro caso. $^{3}$

Los criterios por imágenes (tomografía computada y resonancia magnética), propuestos para el diagnóstico de SDPD son tres: en primer lugar una necrosis o colección en el cuello o cuerpo pancreático de al menos $2 \mathrm{~cm}$. En segundo lugar la presencia de tejido pancreático viable distal a la zona de necrosis. En tercer lugar, el ducto pancreático ingresando a la colección con un ángulo de $90^{\circ} .2,3$

Su confirmación se basa en demostrar la extravasación del material de contraste inyectado en el ducto principal mediante pancreatografía por colangiopancreatografía retrógrada endoscópica (CPRE), ecoendoscopía o bien quirúrgica. ${ }^{2,3}$

Se debe diferenciar esa entidad de la pseudodesconexión, donde existe una compresión extrínseca de tejido pancreático viable, con desplazamiento del ducto principal, el cual contacta con la colección formando un ángulo oblicuo
Copyright $\odot$ 2019, Sociedad Argentina de Radiología. Publicado por Thieme Revinter Publicações Ltda., Rio de Janeiro, Brazil. Todos los derechos reservados.
License terms

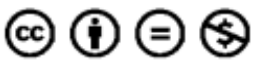



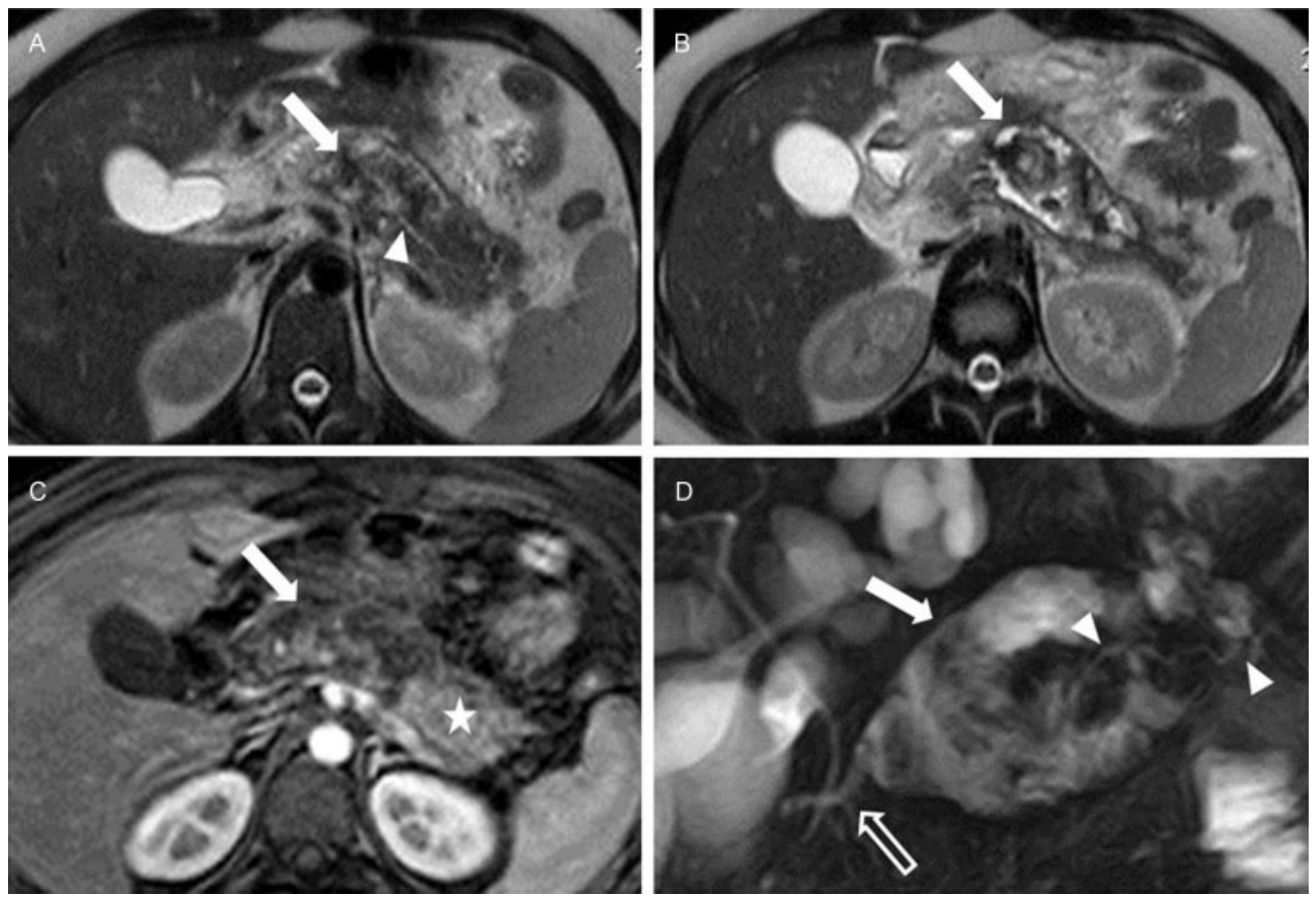

Fig. 1 (A y B) Cortes axiales ponderados en T2 que muestran una colección heterogénea atribuible a una necrosis encapsulada a nivel del cuerpo del páncreas (flecha blanca) y la relación de la colección con el conducto pancreático principal (cabeza de flecha). (C) Axial ponderado T1 FS con gadolinio, muestra tejido pancreático viable con adecuado realce post-contraste en la porción caudal del páncreas (estrella) y la colección a nivel del cuerpo pancreático (flecha blanca). (D) Colangio-RM donde se observa la relación del conducto pancreático principal (cabezas de flecha) con la colección a nivel del cuerpo del páncreas (flecha blanca), a la cual ingresa en un ángulo recto. Se observa además un ducto pancreático de configuración divisum como probable causal (flecha hueca).

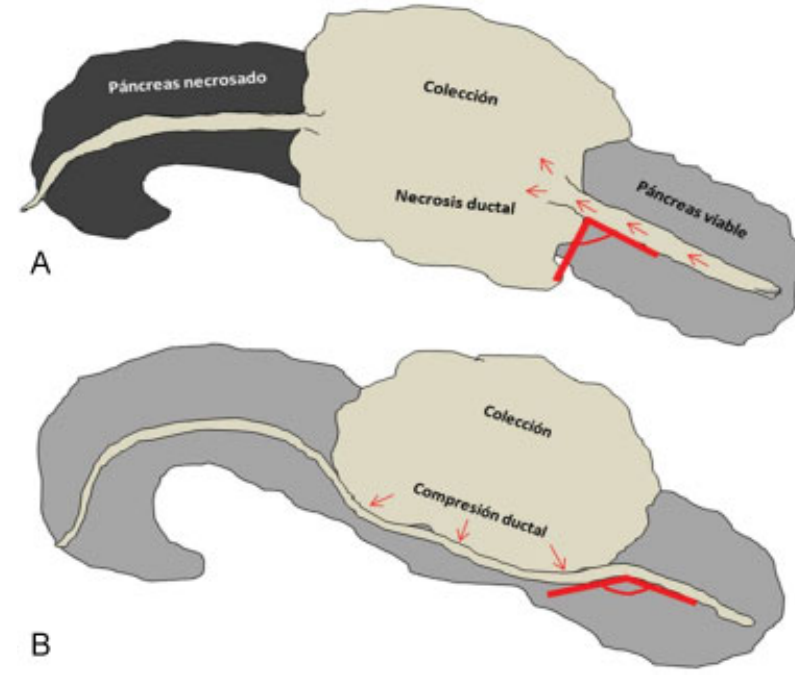

Fig. 2 (A) Esquema que muestra un caso de desconexión ductal donde se observa necrosis de la porción cefálica y cuerpo pancreático, con una colección a nivel del cuerpo la cual contacta con el ducto principal en un ángulo recto. (B) Esquema de una pseudo desconexión donde se observa un "puente" de tejido pancreático viable comprimido por la colección con el consecuente desplazamiento del ducto principal, el cual contacta con la colección en un ángulo obtuso. y no recto como ocurre en los casos de desconexión verdadera (-Fig. 2). ${ }^{1,2}$ Su distinción es relevante debido a las diferencias en la evolución y tratamiento, siendo esos en ambos casos más complejos cuando existe un SDPD. ${ }^{1,2}$

Existen controversias en cuanto al manejo terapéutico de esa entidad, el cual debe valorarse en cada caso en particular. ${ }^{2,3,5-7}$ Existen técnicas endoscópicas como la CPRE con colocación de prótesis y el drenaje interno mediante ecoendoscopía. Ellas son más útiles en los casos donde existe colección, siendo pobres sus resultados en los casos de fístula pancreática externa. ${ }^{2,3}$ Las técnicas quirúrgicas pueden emplearse como primera elección, o ante el fracaso de las técnicas endoscópicas. Entre las opciones quirúrgicas se encuentran las técnicas resectivas como la pancreatectomía distal con o sin esplenectomía, y las derivativas como la fistuloyeyunostomía en Y de Roux, la pancreaticoyeyunostomía o pancreaticogastrostomía, esas últimas mejor toleradas $\mathrm{y}$ con menor índice de complicaciones. $^{1-3,5-7}$

\section{Confidencialidad de los datos}

Los autores declaran que han seguido los protocolos de su centro de trabajo sobre la publicación de datos de pacientes y que todos los pacientes incluidos en el estudio han recibido información suficiente y han dado 
su consentimiento informado por escrito para participar en dicho estudio.

\section{Conflicto de Intereses}

Los autores del trabajo declaran no tener ningún conflicto de intereses.

\section{Bibliografía}

1 Howard TJ, Rhodes GJ, Selzer DJ, Sherman S, Fogel E, Lehman GA. Roux-en-Y internal drainage is the best surgical option to treat patients with disconnected duct syndrome after severe acute pancreatitis. Surgery 2001;130(04):714-719, discussion 719-721

2 Sandrasegaran K, Tann M, Jennings SG, et al. Disconnection of the pancreatic duct: an important but overlooked complication of severe acute pancreatitis. Radiographics 2007;27(05):1389-1400
3 Lawrence C, Howell DA, Stefan AM, et al. Disconnected pancreatic tail syndrome: potential for endoscopic therapy and results of long-term follow-up. Gastrointest Endosc 2008; 67(04):673-679

4 Murage KP, Ball CG, Zyromski NJ, et al. Clinical framework to guide operative decision making in disconnected left pancreatic remnant (DLPR) following acute or chronic pancreatitis. Surgery 2010;148 (04):847-856, discussion 856-857

5 Varadarajulu S, Wilcox CM. Endoscopic placement of permanent indwelling transmural stents in disconnected pancreatic duct syndrome: does benefit outweigh the risks? Gastrointest Endosc 2011;74(06):1408-1412

6 Devière J, Antaki F. Disconnected pancreatic tail syndrome: a plea for multidisciplinarity. Gastrointest Endosc 2008;67(04): 680-682

7 Howard TJ, Stonerock CE, Sarkar J, et al. Contemporary treatment strategies for external pancreatic fistulas. Surgery 1998;124(04): 627-632, discussion 632-633 